\title{
SUCCESSFUL AIRWAY MANAGEMENT OF A CASE OF MULTINODULAR GOITER ASSOCIATED WITH TRACHEAL NARROWING AND DEVIATION WITH FIBER OPTIC BRONCHOSCOPE
}

Sony Sharma ${ }^{1}$, Natesh S Rao², Sadanand Gopal ${ }^{3}$, Rahul Bansal ${ }^{4}$

\section{HOW TO CITE THIS ARTICLE:}

Sony Sharma, Natesh S Rao, Sadanand Gopal, Rahul Bansal. "Successful Airway Management of a Case of Multinodular Goiter Associated with Tracheal Narrowing and Deviation with Fiber Optic Bronchoscope". Journal of Evolution of Medical and Dental Sciences 2014; Vol. 3, Issue 70, December 15; Page: 14997-15001, DOI: $10.14260 /$ jemds/2014/4016

ABSTRACT: BACKGROUND: The thyroid gland is an important endocrine gland of the body placed anteriorly in the neck just in front of $3^{\text {rd }}, 4^{\text {th }} \& 5^{\text {th }}$ tracheal cartilage. Enlargement of this gland causes narrowing and deviation of trachea leading to difficulty in breathing. Hence the anaesthetic management of this patient can be challenging. CASE: A 68 years old lady with cervical multinodular goiter who had left hemithyroidectomy done 20 years ago has now come with complain of a swelling in front of the right side of neck with shift of trachea to left. In order to avoid airway compromise with the induction of anaesthesia fibreoptic bronchoscope (FOB) was used to secure the airway. A wake intubation with $6 \mathrm{~mm}$ endotracheal tube via nasal root was done. Patient was kept intubated in view of tracheomalacia and shifted to ICU. Extubated after 24 hours after demonstrating leak test using fiberoptic bronchoscope for direct visualization of trachea. CONCLUSION: FOB is considered a gold standard in this situation. Extubation in ICU is essential to rescue the airway if tracheal collapse occurred.

KEYWORDS: Multinodular goiter, Fiberoptic Bronchoscope, Intubation, Extubation, Tracheomalacia.

INTRODUCTION: A long standing goiter can lead to deviation and narrowing of trachea. Preoperative anesthetic assessment often diagnoses a difficult intubation.1,2 In such case, induction of general anesthesia leads to difficulties in endotracheal intubation and even face mask ventilation. ${ }^{3}$ Fiberoptic intubation (FOI) has been reported successfully in patients with enlarged thyroid in a difficult airway situation. ${ }^{4,5}$ Flexible fiberoptic intubation is usually considered as the gold standard in patients with anticipated difficult airway.6,7

CASE REPORT: A 68 years old lady weighing $48 \mathrm{~kg}$ reported to the hospital with a progressively increasing painless swelling in front of the neck with no features suggestive of hypo or hyperthyroidism nor did she have any difficulty in swallowing, breathing or any hoarseness of voice. She had undergone left-hemithyroidectomy 20 years ago. Her clinical examination revealed a regular pulse rate of $82 / \mathrm{min}$, BP $110 / 70 \mathrm{mmHg}$, respiratory rate of $16 / \mathrm{min}$. Systemic examination revealed a normal cardiovascular, respiratory and central nervous system. Local examination revealed a hard nodular adherent swelling of $3 \times 3 \mathrm{~cm}$ on the right side of thyroid region with prominent sternocleidomastoid and cervical lymphadenopathy on the right side (Figure 1). Bilateral carotid pulsation was felt. ECG, chest X-ray and blood investigation were normal. FNAC showed colloidal goiter with calcification. X-Ray neck showed tracheal deviation to left with indentation and calcification of thyroid gland (Figure 2). CT-Scan showed a calcified swelling arising from the right lobe of isthmus and infiltrating to surrounding soft tissue (Figure 3). 


\section{CASE REPORT}

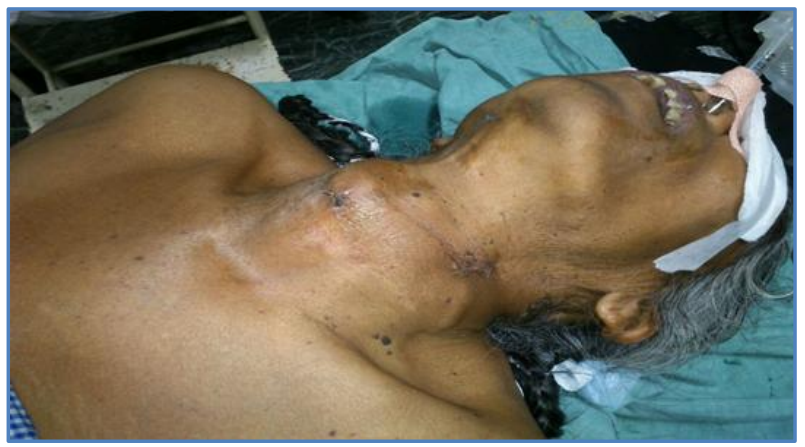

Fig. 1: photograph of patient before surgery

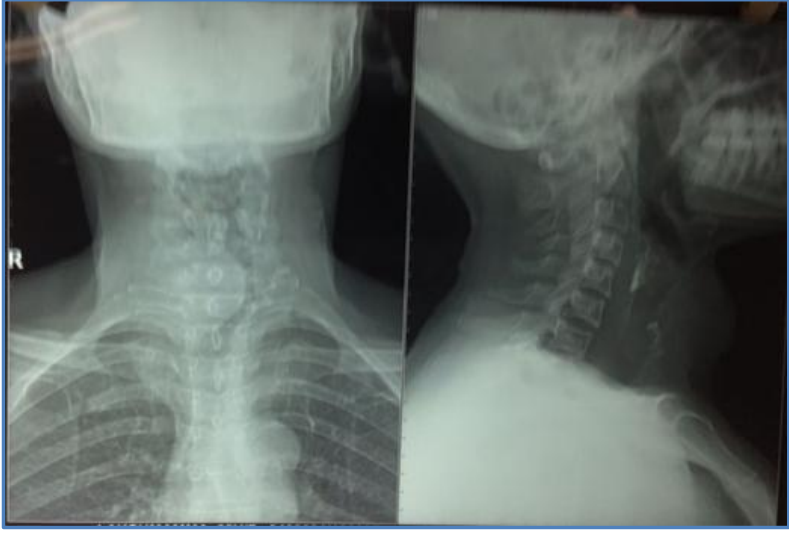

Fig. 2: X-ray showing tracheal compression and deviation to left in AP-view but no narrowing in lateral view

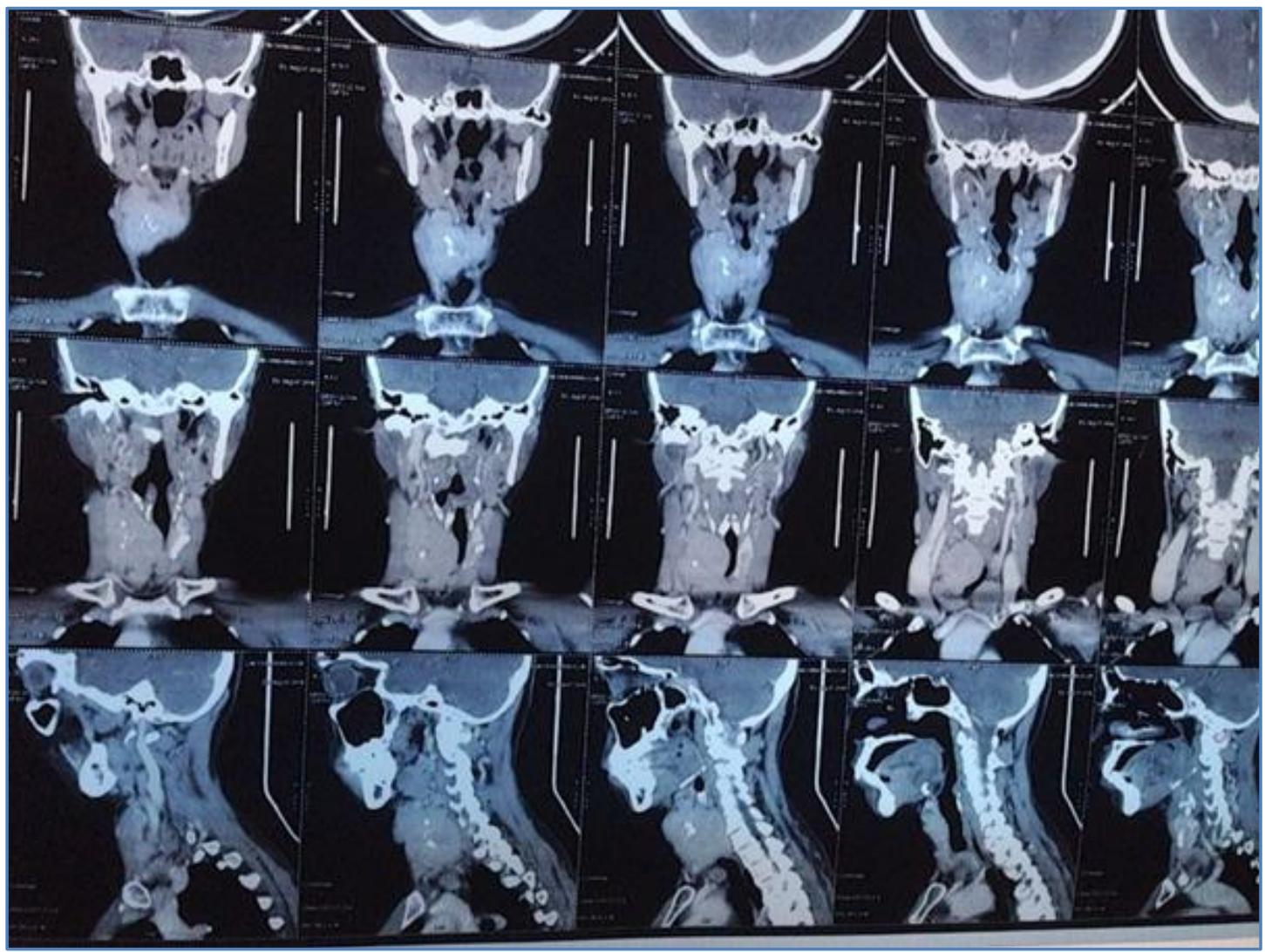

Fig. 3: CT-Scan showing distortion of the trachea by goiter

In view of deviation and narrowing of trachea awake nasal intubation with a Fiberoptic Bronchoscope (FOB) was planned and it was also planned to be used for extubation, so that postoperatively the trachea could be visualized and rescued if any tracheal collapse occurred. 
The procedure was explained to the patient and written consent was taken. Patient kept nil per oral 6 hour, premedication was given and standard monitors attached (ECG, Spo $2, \mathrm{ETCO}_{2}$, NIBP and temperature probe).

Patient's airway was prepared by instilling Xylometazoline in both nostril for vasoconstriction of nasal passage and to reduce the risk of bleeding, giving lignocaine $2 \%$ viscous gargle and nebulization for $15 \mathrm{~min}$ with $4 \mathrm{ml}$ of $4 \%$ lignocaine. ${ }^{8}$

Endotracheal-tube (ET-tube) was mounted on to the FOB, oxygen was attached to side port of FOB and suction connected. A $10 \mathrm{ml}$ syringe was loaded with $2 \%$ lignocaine for spraying when required. The FOB was advanced via the patent nostril towards the laryngeal inlet. Once the laryngeal and oesophageal inlet were visualized, the scope was negotiated through the vocal cord, the insertion of the FOB was difficult beyond the cord due to deviation and significant narrowing of trachea (Figure $4 \& 5$ ). So, slowly FOB was negotiated through the constriction which was nearly $3 \mathrm{~cm}$ length of trachea and advanced towards the carina. A $6 \mathrm{~mm}$ ET-tube was advanced over the FOB with difficulty and slowly the FOB was removed. Breathing circuit was attached and position of tube confirmed again by auscultation over the chest \& $\mathrm{ETCO}_{2}$. The patient was induced with $80 \mathrm{mg}$ of propofol, $100 \mathrm{mcg}$ of fentanyl and $4 \mathrm{mg}$ of vecuronium. Anaesthesia was maintained with oxygen: air (1:2), sevoflurane $2 \%$, vecuronium and fentanyl.

Right thyroidectomy was planned but due to calcification and adhesion to trachea only superficial part of the gland was removed.

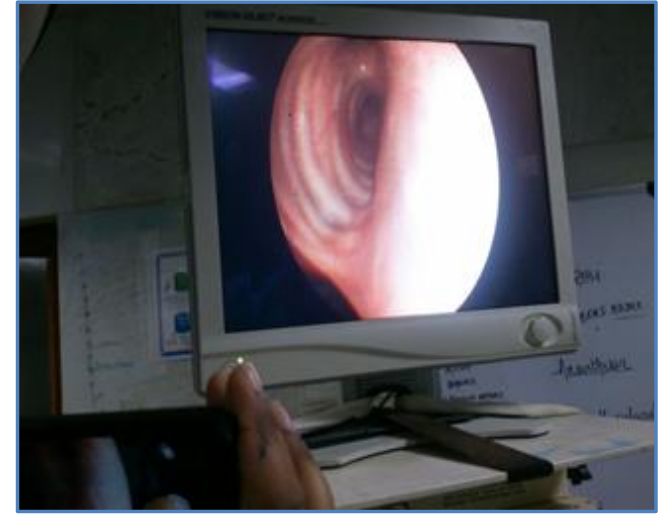

Fig. 4: Fiberoptic view of trachea showing starting of narrowing

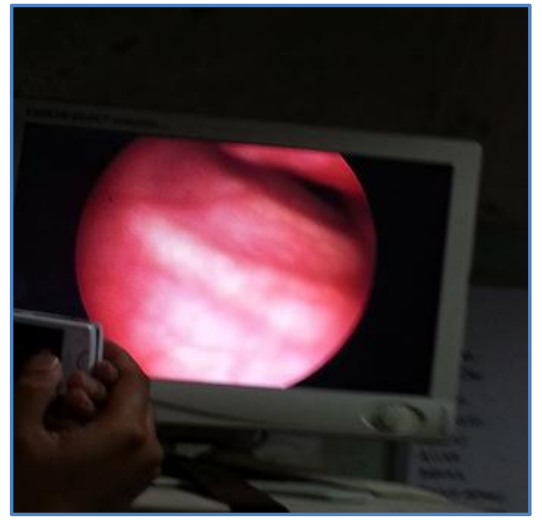

Fig. 5: Fiberoptic view of trachea showing indentation and narrowing

Patient was not extubated postoperatively and was shifted to ICU in view of probable tracheomalacia and localized edema due to surgery. Extubation was done next day after checking for adequate neuromuscular reversal and demonstrating leak around the tracheal tube after the tracheal tube cuff was deflated. Patient was ventilated with $100 \%$ oxygen for $3 \mathrm{~min}$ and proper oro-pharyngeal suction was done. Injection fentanyl $60 \mathrm{mcg}$ was given to allay anxiety and injection glycopyrrolate to decrease secretion. After connecting Oxygen to the side port of FOB, the FOB was passed through the ET-tube till the carina and then slowly withdraws to visualize the end of ET-tube. Once the end of the ET-tube was visible, the ET-tube was slowly withdrawn so that the trachea was seen along the course as extubation was done. After extubation the patient was observed for stridor, respiratory distress and then shifted to ward. 
DISCUSSION: Benign multi-nodular goiter is a common problem affecting $5 \%$ of the general population in non-endemic and $15 \%$ in endemic area. However, the incidence of benign goiter causing acute airway obstruction is as low as $0.6 \% .{ }^{9}$ When a goiter is purely cervical, it rarely compresses the trachea to cause obstruction. ${ }^{10}$ The progressive, insidious growth allows the patient time to compensate for up to $70 \%$ of tracheal compression. ${ }^{10}$ This may be the reason why the lady had no respiratory obstruction due to tracheal narrowing as it had progressed over 20 years. The presence of tracheal compression and/or stenosis in goiter patient may be an aggravating factor for difficult endotracheal intubation, making an indication for fiberoptic intubation. ${ }^{11}$ Fiberoptic intubation is always indicated in goiter when tracheal deviation and clinical symptom of tracheal compression and/or stenosis are present.12,13

The thyroid swelling was not so large when compared to the significant compression and shift of the trachea. Thus in view of difficult ventilation and intubation, FOB was planned. Patient was electively kept intubated for 24 hours in view of tracheomalacia, tracheal narrowing and surrounding soft tissue edema. The patient was extubated under direct vision using FOB, so that during extubation if any problem occurred, airway obstruction could be avoided by placing the ET-tube to its original position. In spontaneously breathing patient, extubation over a broncoscope offers the possibility of visually assessing the vocal cord function. It also permits an assessment of anatomic injury to the trachea, glottis or supraglottic structure. ${ }^{14}$ There are a large number of complications associated with routine extubation and difficulties with reintubation might be expected. Hence, Extubation was planned under direct vision using FOB. During extubation it was evident from the FOB view that there was no tracheal indrawing nor collapse of trachea from inspiration. The distorted anatomy of trachea was seen, there was indentation on the right side but the airway patency was maintained. Hence the ET-tube was removed.

SUMMARY: FOB is an established tool to manage airway in case of difficult intubation from thyroid mass. It is also useful to explore the supra and infra-glottic region both during intubation and extubation.

Management of the difficult airway does not end with the placement of an endotracheal tube. It is important to emphasis that the difficult airway has to be successfully managed until the trachea is safely extubated.

\section{REFERENCES:}

1. Benumof JF. Management of the difficult adult airway. With special emphasis on awake tracheal intubation. Anesthesiology. 1991; 75: 1087-110. Article PubMed.

2. Apfelbaum JL, Hagberg CA, Caplan RA, Blitt CD, Connis RT, Nickinovich DG, Benumof JL, Berry FA, Bode RH, Cheney FW, Guidry OF and Ovassapian A. Practice guidelines for management of the difficult airway: an update report by the American Society of Anesthesiologists Task Force on Management of the Difficult Airway. Anesthesiology.2013; 118:251-70. Article. PubMed.

3. Bouaggad A, Nejmi SE, Bouderka MA and Abbassi O. Prediction of difficult tracheal intubation in thyroid surgery. Anesth Analg. 2004; 99: 603-6. Article Pub Med.

4. Amathieu R, Smail N, Catineau J, Poloujadoff MP, Samii K, Adnet F. Difficult intubation in thyroid surgery: Myth or reality ? Anesth Anesth Analg 2006; 103:965-8. 
5. Hariprasad M, Smurthwaite GJ. Management of a known difficult airway in a morbidly obese patient with gross supraglottic oedema secondary to thyroid disease. Br J Anaesth 2002; 89: 927-30.

6. Ovassapian A. Fiberoptic endoscopy and the difficult airway. Philadelphia: Lippincott-Raven Press; 1996.

7. Ovassapian A, Tuncbilek M, Weitzel EK, Joshi CW. Airway management in adult patient with deep neck infection: a case series and review of the literature. Anesth Analg 2005; 100: 585-9.

8. Divya Srivastava, Sanjay Dhiraaj. Airway management of a difficult airway due to prolonged enlarged goiter using loco-sedative technique. Saudi Journal of Anaesthesia2013, vol 7, issue 1.

9. Rios A, Rodrlguez JM, Canteras M, Galindo PJ, Tebar FJ, Parrila P: Surgical management of multinodular goiter with compressive symptoms. Arch Surg 2005, 140:49-53.

10. Sajja LR, Mannam GC, Sompalli S, Simhadri CSR, Hasan A: Multinodular goiter compressing the trachea following open heart surgery. Asian Cardiovasc Thorac Ann 2006, 14:416-417.

11. Mc Henry CR, Piotrowski JJ.Thyroidectomy in patients with marked thyroid enlargement: airway management, morbility and outcome. Ann Surg 1994; 60: 586-91.

12. Mazeres JE, Lefrance A, Cropet C, Steghens A, Bachmann P, Perol O, Rosay H. Evaluation of the Bonfils intubating fiberscope for predicted difficult intubation in awake patients with ear, nose and throat cancer. Eur J Anaesthesiol 2011; 28: 646-50.

13. Kovacs G, Law J.A, Petrie D.Awake fiberoptic intubation using optical stylet in an anticipated difficult airway. Ann Emerg Med 2007; 49: 81-3.

14. Delling RP: Fiberoptic bronchoscopy in adult airway management. Crit Care Med 1990; 18: 882.

\section{AUTHORS:}

1. Sony Sharma

2. Natesh S Rao

3. Sadanand Gopal

4. Rahul Bansal

\section{PARTICULARS OF CONTRIBUTORS:}

1. Senior Resident, Department of Anaesthesiology, Vydehi Institute of Medical Science and Research Center, Whitefield, Bangalore.

2. Professor, Department of Anaesthesiology, Vydehi Institute of Medical Science and Research Center, Whitefield, Bangalore.

3. HOD, Department of Anaesthesiology, Vydehi Institute of Medical Science and Research Center, Whitefield, Bangalore.
4. Post Graduate Student, Department of Anaesthesiology, Vydehi Institute of Medical Science and Research Center, Whitefield, Bangalore.

\section{NAME ADDRESS EMAIL ID OF THE CORRESPONDING AUTHOR:}

Sony Sharma,

Kondappa Building,

KSVK School Road,

Vinayaka Nagar, $5^{\text {th }}$ Cross,

Whitefield, Bangalore.

Email: hitanu02@yahoo.co.in

Date of Submission: 04/12/2014.

Date of Peer Review: 05/12/2014.

Date of Acceptance: 10/12/2014.

Date of Publishing: 15/12/2014. 